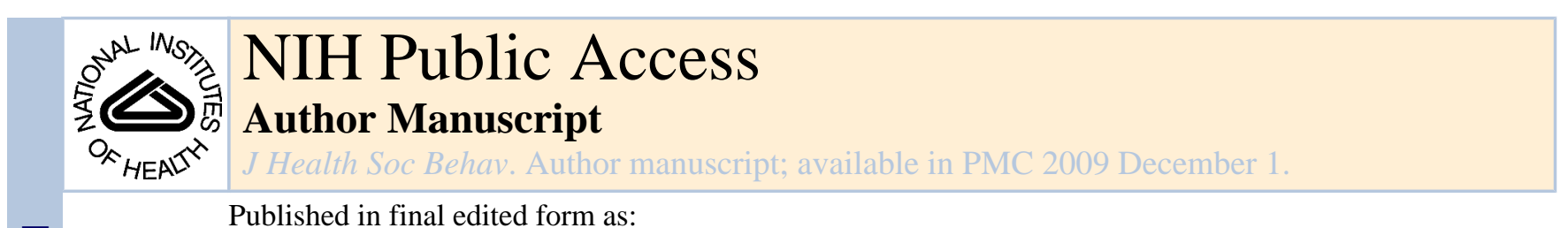

Published in final edited form as:

J Health Soc Behav. 2008 December ; 49(4): 417-435.

\title{
Pollution Comes Home and Gets Personal: Women's Experience of Household Chemical Exposure ${ }^{*}$
}

\author{
Rebecca Gasior Altman, \\ Brown University \\ Rachel Morello-Frosch, \\ University of California at Berkeley \\ Julia Green Brody, \\ Silent Spring Institute \\ Ruthann Rudel, \\ Silent Spring Institute \\ Phil Brown, and \\ Brown University \\ Mara Averick \\ Brown University
}

\section{Abstract}

We report on interviews conducted with participants in a novel study about environmental chemicals in body fluids and household air and dust. Interviews reveal how personal and collective environmental history influence the interpretation of exposure data, and how participants fashion an emergent understanding of environmental health problems from the articulation of science and experience. To the illness experience literature, we contribute a framework for analyzing a new category of embodied narratives- "exposure experience"-that examines the mediating role of science. We update social scientific knowledge about social responses to toxic chemicals during a period in which science alters public understanding of chemical pollution. This article is among the first published accounts of participants' responses to learning personal exposure data, research identified as critical to environmental science and public health. Our findings raise the importance of reporting even uncertain science and underscore the value of a community-based reporting strategy.

Science increasingly contributes to how people discover and understand environmental problems (Murphy 1997), both aside from and in addition to their embodied or direct experience. Biomonitoring science and personal exposure assessment, which measures environmental chemicals 1 in the human body and household air and dust, is one example where

\footnotetext{
* This research was supported by National Institute of Environmental Health Sciences grant 1 R25 ES013258-01 and National Science Foundation grant SES-0450837. The authors extend their thanks to Cheryl Osimo, David Long, and Liesel Seryak for their assistance in coordinating the study, and to Laura Senier, Jessica Nelson, Madeleine Kangsen Scammell, Elizabeth Hoover, Crystal Adams, The Contested Illness Research Group, and the anonymous $J H S B$ reviewers for insightful feedback on earlier drafts.

Address correspondence to Rebecca Gasior Altman, Department of Sociology, Box 1916, Brown University, Providence, RI 02912 (email: E-mail: Rebecca_Altman@alumni.brown.edu).

Publisher's Disclaimer: Please Note: This is an author-produced, peer-reviewed article that has been accepted for publication in The Journal of Health and Social Behavior but has not undergone final copyediting. The publisher-authenticated version will be available at http://www.asanet.org.
} 
science shapes public perceptions about environmental problems, as a flood of new studies shifts concern about environmental pollution from outdoors to indoors (Clarke 1989; Murphy 2006), and from rivers to veins (Fischer 2006). For example, the U.S. Centers for Disease Control reports on 148 chemical pollutants in the blood or urine of the general U.S. population, including pesticides, flame retardants, and plastic additives (CDC 2005), and they expand the scope of their search each year. ${ }^{2}$

Biomonitoring and household exposure information has become more widely available for public consumption. In addition to regular reports from the CDC (2005), some communitybased exposure studies present participants with personal data as well as aggregate study results (Brody et al. 2007). Similarly, in response to government surveillance programs that report population averages, social movement organizations conduct exposure studies and publicize volunteers' results using interactive websites. These feature participants' results alongside pictures and biographies that put a human face to the rising tide of exposure data collected by governments (see Environmental Working Group 2003; also Brown 2007; Washburn 2007a). Both types of studies come with substantial uncertainties, though, leading to debate about whether and how results should be reported to the public. For many of the chemicals, scientists do not yet know at what concentration they may pose health risks; and scientists often cannot "fingerprint" the contribution of specific sources or recommend evidence-based strategies for reducing individual exposure when exposures are ubiquitous and products poorly labeled.

Though there has been a rapid increase in exposure assessment using these techniques, there has not been a parallel rise in social science that investigates their significance. In particular, how people respond to personal exposure data remains largely unknown (exceptions include Quandt et al. 2004; Usher et al. 1995), ${ }^{3}$ leading the National Research Council to identify this as an important research need (2006).

In the context of a study that sampled for 89 environmental chemicals in 120 homes and biological samples, we examined how people assign meaning to their results. This study is among the first to investigate the experience of results reported to study participants in biomonitoring and exposure assessment studies, and the first such study to apply the tools and perspectives of medical sociology. In this article, we elucidate a new embodied health experience that adds to the medical sociology literature on illness by developing a framework for studying "exposure experience." In addition, examining exposure science represents a unique opportunity to track changing public knowledge about the accumulation of synthetic chemicals and industrial by-products. For the past two decades, research on social responses to pollution typically examines specific contamination events, whether from acute disasters or chronic pollutant leaks or releases. Here, we study responses to pollution from household activities and products that previously have been the unexamined backdrop to everyday life in consumer societies: electronics, carpeting, cleaners, beauty products, and so on (Lioy, Freeman, and Millette 2002). Moreover, as we demonstrate, science—not just the direct experience of environmental problems-shapes participants' embodied health experiences. This finding suggests future opportunities for social scientists to expand the illness experience literature by characterizing diverse exposure experiences, how they vary, and how they are mediated by environmental science.

\footnotetext{
${ }^{1}$ We define environmental chemicals as materials extracted or synthesized in the industrial production of "goods and services that support consumer economies" (Geiser 2001:15), including agricultural production and military applications.

${ }_{2}^{2}$ See the list of chemicals measured in the 2003-2004 National Health and Nutrition Examination Study (NHANES 2007).

$3^{3}$ Notable exceptions include: (1) the 2006 Consensus Conference on Biomonitoring sponsored by the Boston University School of Public Health (see www.biomonitoring06.org), (2) a federally funded epidemiologic study of perflourinated compound in an Ohio factory community, which includes extensive ethnographic evaluation of community responses by Mary Hufford from the University of Pennsylvania (see www.lhwc8study.org), and (3) the doctoral research conducted by Rachel Washburn (2007a; 2007b).
} 


\section{Background and Conceptual Framework for Analyzing Participant Responses}

\section{Indoor Pollution as a New Exposure Experience}

Early research on the embodied experience of pollution involved case studies of acute contamination crises, industrial disasters, and disease clusters surrounding one predominant exposure source. Social scientists found that these chemical exposure scenarios disrupt community identity, social relations, and connections to place, and they prompt widespread fear and anxiety (Bullard 1990; Couch and Kroll-Smith 1991; Edelstein 2004; Erikson 1994). They attributed such responses to the historical absence of popular knowledge that could inform communities' concerns and help them anticipate strategies for remediation (Erikson 1994). However, over time, popular knowledge about environmental problems has evolved, as the media increasingly reported on environmental problems and research deepened collective understanding about human-environment interaction (Szasz 1994).

Couch and Kroll-Smith $(1985,1991)$ developed the concept "chronic technological disaster" to characterize a different exposure scenario. They pointed to the emergence of other categories of environmental problems that develop over time and are often not noticeable under routine conditions. Public responses to these equally insidious but emergent environmental problems were far more muted. Beamish (2002), like Clarke (1989) before him, added to these insights by specifying how assumptions built from an institutional, organizational, and popular preoccupation with large-scale disasters shaped the exposure experience in ways that constrained citizens from recognizing and acting on more ambiguous, chronic environmental problems.

Our work goes one step further by shifting the location of the chronic exposure experience from "out there" to inside homes and bodies. This is not to imply that science and concerned citizens overlooked the personal implications of environmental contamination. Social scientists have documented that citizens and workers, from the Industrial Revolution forward, feared for their health and turned to science to assuage those fears (Brown and Mikkelsen 1990; Gottlieb 2005; Levine 1982). The relatively new "home front" of environmental pollution generates a different exposure experience. For those living in contaminated communities, contact with the contamination source is powerful because immediate, e.g., the chemical plume underneath one's home or chemicals entering through the kitchen tap. However, contrast these experiences with the knowledge that environmental chemicals have transgressed the boundaries of home and body, and that they are detectable in urine samples and household dust collecting beneath the sofa.

Furthermore, the expanded use of biomonitoring and exposure science has altered the relationships among exposed populations, science, and chemicals, and leads to a different exposure experience. During the 1980s, citizens' requests for personal exposure data often exceeded what exposure science could offer them (Harris 1983), so in many instances there were few data, if any, for citizens to interpret. When exposure studies were conducted, they measured how community exposures differed from a control or reference population, but people living in contaminated communities rarely faced data that quantified their unique, personal exposure, and certainly not from products that they had brought into their home. Finally, in these historical cases, exposure science was used to verify or quantify exposure to an extant problem "discovered" by the community. Murphy (1997), however, describes a host of other environmental conditions, like ozone depletion, that are largely unknowable, unless scientists (in some instances directed by activists or communities) went looking for them. In the case of household pollutants and chemical body burden, science has been the primary means through which embodied and indoor pollution have been "discovered." 
To summarize, rapid technological innovation in exposure assessment science has combined with new science-based and advocacy-based strategies that treat scientific information as a public right-to-know (Brody et al. 2007; Morello-Frosch et al. 2006). Together, these trends alter how some people experience environmental pollution. Personal exposures to chemical pollutants in homes and bodies, then, can be thought of as a "new species of [environmental] troubles" (Erikson 1994) where science plays a paramount role in discovering and defining problems that often are not, on their own, perceptible through direct experience.

However, though exposure science has expanded much in recent years, social science knowledge has not kept pace in updating the implications such findings have on the embodied experience of environmental problems. Prior research details an exposure experience predominantly characterized by disrupted lives, fear, and anxiety (e.g., Edelstein 2004; Vyner 1989). While these insights remain relevant today, it is important to recognize that they were developed by observing responses to environmental disasters and catastrophes that differ from the exposure experience we present here. Our research investigates this new exposure experience to update scientific understandings about the range of social responses to environmental health problems during a time in which science increasingly shapes that experience.

\section{Science, Exposure Experience, and Environmental Consciousness}

Our approach builds on the study of human illness experience, a cardinal area of research within medical sociology (e.g., Bird, Conrad, and Fremont 2000; Lawton 2003). In this article, we offer "exposure experience" as a new category of embodied experience that is becoming increasingly common as more individuals, communities, and populations learn about chemicals in their bodies and everyday environments.

We also contribute a framework for studying how scientific understanding and embodied experiences emerge through one another, which reflects what Jasanoff (2004) refers to as the co-production of science and society. Within medical sociology, the illness experience literature has tended to focus on direct experience with symptoms or the health care system, and to a lesser extent on how science intersects with and informs individuals' embodied and illness experiences, although this is changing. One emerging trend in medical sociology research examines how technologies like medical imaging and genetic screening raise individuals' awareness of subclinical health effects or predispositions for disease in advance of physical symptoms (e.g., Cox and McKellin 1999; Robertson 2000). Though this research informs our work, these studies vary in the extent to which they bring science and technology into analytic view (Timmermans and Berg 2003), and thus offer few clues for examining the dynamic interaction between individual experience and science and technology.

To assess the meaning of science for exposure experience, we start from an assumption that exposure science characterizes an objective reality (e.g., chemical body burden) rather than reflecting a socially constructed artifact. However, though we adopt this middle-ground stance toward the scientific enterprise, our analytic focus is, at the same time, on the social processes that shape the meaning and significance of that information. To understand these interpretative processes, we draw from the literature on the public understanding of science, which informs us that the lay public rely on a wide array of knowledge and experience to interpret complex science (Irwin and Wynne 1996), often through an interactive and relational process rather than a purely didactic and cognitive one (Wynne 1996). From Hilgartner and Bosk (1988) we expect that participants would consult three sources of social knowledge, with prior encounters with toxicants being paramount: (1) interactions with professionals, researchers, family, and friends, (2) knowledge gleaned from the media or social movement discourse, and (3) experiential knowledge, in particular, experience with other environmental, health, or social problems. Most importantly, environmental sociology and psychology inform us that when 
dealing with environmental issues, individuals look to prior experiences for cues about how to respond (Couch and Kroll-Smith 1991; Edelstein 2004). Therefore, we considered what role past environmental experiences played in participants' interpretations, what Edelstein (2004) terms "eco-social" history.

When we look across participants' exposure experience narratives, we attempt to understand in what ways "eco-social history" operates as a collective or shared set of assumptions: a common pool of accumulated knowledge about chemicals and environmental problems drawn from community relations, collectively experienced contamination episodes, media or movement discourse, or from other collective experiences. These experiences coalesce into a popularly available set of assumptions, social cues, and social referents that individuals draw upon to guide new encounters with chemical pollutants. These popular assumptions, in turn, inform how participants understand risks, anticipate government and societal responses, and respond to the situation.

We further define the eco-social and historical context as encompassing participants' past experience with pollution — or the lack thereof — and also the power relationship between the pollution source and the exposed population (Pulido 1996; Edelstein 2004). As the distribution of environmental pollution varies across populations and places (Morello-Frosch 2002), we suspect that communities will have different eco-social histories that will differentially filter and inform their responses to data about chemicals in homes and bodies.

However, sociology also reminds us that certain implications follow from such a reliance on past experience to inform contemporary circumstances (Clarke 1989; Beamish 2002). For example, in a study of public responses to a slow oil leak off the coast of San Luis Obispo County, California, Beamish (2002) found that residents, workers, and government officials, all witnesses to the leak, did not express dread or panic. Rather, they had a more measured response, and in some cases were unresponsive, until over a period of forty years the oil grew into one of the largest oil spills in U.S. history. Beamish concludes that prior environmental encounters prime individuals to respond more readily to acute contamination crises, particularly those preceded by an attention-grabbing event, such as a fire, spill, or explosion, and to overlook or become habituated to evidence of more ambiguous environmental problems. Hence prior experiences channel attention away from chronic yet insidious environmental problems, often until they become disastrous in proportion. We believe this latter scenario better approximates the situation of receiving personal exposure results, where study participants learn about the build-up of chemicals in their most intimate environments. This suggests that past experiences can be powerful shapers of current scientific information, and in this article we explore the implications that this interaction between science and experience has for study participants' embodied experiences of and responses to environmental health problems.

As environmental sociology has directed scholarly attention to the health and social implications of pollution, it has found common ground with medical sociology. This convergence between the substantive concerns of these subfields is evidenced by a burgeoning literature that integrates environmental and medical sociology, with science serving as a key bridge (Brown 2007; Casper 2003; Kroll-Smith and Floyd 1997; McCormick, Brown, and Zavestoski 2003; Zavestoski, Brown, and McCormick 2004). Our development of the concept "exposure experience" builds on numerous articulations between medical and environmental sociology, such as the study of health-based social movements (Brown, Zavestoski, McCormick et al. 2004), place-based health (MacIntyre, Ellaway and Cummins 2002), environmental trauma (Edelstein 2004; Erikson 1994; Couch and Kroll-Smith 1991), and environmental suffering (Auyero and Swistun 2007). Similarly, our work is situated within the 
extensive literature on environmental health within environmental sociology (e.g., KrollSmith, Brown, and Gunter 2000).

\section{Data and Methods}

\section{The Silent Spring Institute Household Exposure Study}

Our qualitative study of women's responses to personal exposure information is one component of a collaborative, interdisciplinary research project to investigate possible links between environmental exposures and breast cancer (see Rudel et al. 2003). One portion of this effort - the Household Exposure Study (HES) — is designed to characterize common chemical exposures in everyday, indoor environments, which are poorly understood (see U.S. General Accounting Office 1999). This research uses community-based participatory research methods that emphasize right-to-know so that study participants had the option to learn their own as well as aggregate results (Brody et al. 2007). Participants in the original HES were drawn from an earlier case-control breast cancer study of Cape Cod women diagnosed between 1988 and 1995.

The Household Exposure Study began with air, dust, and urine sampling of 120 homes on Cape Cod, a region of Massachusetts with elevated rates of breast cancer (McKelvey et al. 2003). Samples were analyzed for 89 chemicals that affect hormones, including alkylphenols, parabens, phthalates, polychlorinated biphenyls (PCBs), flame retardants, pesticides, and phenols. ${ }^{4}$ The researchers surveyed participants about building materials in their homes and use of cleaning and personal care products. Researchers later resampled a subset of homes with elevated contaminant levels of PCBs, chlordane (a pesticide), and the flame retardant (2, 3dibromopropyl) phosphate Tris, all banned substances in the United States. Blood samples were tested for PCBs in participants whose homes had high levels. The study was the first to report indoor measures for 30 of these chemicals (Rudel et al. 2003), and it was also among the first to report both community and individual-level exposure data to study participants.

Participants were asked during the informed consent process whether they wanted to receive their results. In fall 2004, scientists reported results to the 97 percent of participants who requested them. Report-back included a cover letter, a narrative results summary, and graphs (see Figure 1) that showed the concentration of chemicals found in each home compared to the distribution of the entire sample and to U.S. Environmental Protection Agency (EPA) exposure guidelines, although such guidelines were only available for about half of the chemicals. ${ }^{5}$ The scientists enclosed a table of what household products and industrial or household practices were common exposure sources. Women whose homes were sampled a second time received follow-up results by mail in November 2005, and a member of the study team phoned each of them.

\section{Follow-Up Interviews to Elucidate Participants' Experiences}

Sample selection and characteristics of participants-We interviewed a subset of women who had participated in the Silent Spring Institute's Household Exposure Study. Since the Silent Spring Institute had drawn their HES sample from an earlier breast cancer study, the majority of HES participants were 80 years of age or older; so in order for our qualitative follow-up study to represent women across the life course, we stratified all HES participants by age and over-sampled younger women for inclusion in our interview sample. We selected 37 women who had requested their results during the HES informed consent, who were still

\footnotetext{
${ }^{4}$ These chemicals were selected because they are produced in large volume, found in common household materials and products, and are suspected or known to disrupt hormones (see Rudel et al. 2003).

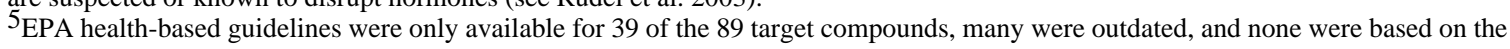
potential for hormonal effects, which was the reason for inclusion in the study.
} 
living in the area, and who had complete contact information. One had died, five declined to participate, and $25(83 \%)$ completed interviews, representing 20 percent of HES participants. Among women who were interviewed, eight were 59 or younger, 14 were between 60 and 79, and three were 80 or older. Half the women interviewed had a college education or higher; 33 percent had some college or vocational education, and 17 percent ended their schooling with high school graduation. The women owned their homes. Although we did not ask how many were mothers, 80 percent had given birth. Three-fourths had been diagnosed with breast cancer, and others reported a range of familial health issues, from Lou Gehrig's disease to other forms of cancer.

Interview schedule and procedure-We conducted 30 interviews with 25 individuals between June 2005 and May 2006. ${ }^{6}$ Interviews were conducted within six months of the time that the women received their initial HES results; to refresh participants' memory, we mailed a second copy of results just before the interview. Five women were interviewed again after their homes and urine were resampled. The interviewer was blinded to the participants' exposure data, unless they shared their results or requested assistance with reading the graphs. ${ }^{7}$ The interview schedule (available upon request) included 55 semi-structured questions about participants' interpretation of exposure results, impressions of the key findings, what the results told them about their home and health, and what responses, if any, the results prompted. Interviews lasted 40-90 minutes.

\section{Analysis}

Interviews were first recorded and transcribed, then all project documents were imported into NVivo 1.2, a qualitative data management and analysis tool. Coding began with a preestablished set of codes drawn from the literatures on public understanding of science, the social responses to environmental contamination, and the "discovery" of social problems (codes are available upon request). We assigned these codes to recurring themes, with a focus on (1) how participants interpret and act on exposure data and (2) what social cues or referents the participants invoked. Additional themes that emerged from the interviews were recoded using free coding and memo-writing. A secondary coder reviewed all transcripts and a subsample of codes for verification and to specify patterns and themes.

\section{Results}

Study participants reported gaining a new or expanded understanding of their everyday exposure to environmental chemicals. Participation in the study led participants to conclude at least one but often several of the six following points:

1. Synthetic chemicals can be detected in household air and dust, and in human samples such as urine (e.g., "There's chemicals everywhere in this place!")

2. Most homes have chemicals. Many extended this message to assume that most homes, including homes outside the study, harbored similar chemicals, too. (e.g., "I just figured that was the way it was in every house.")

3. Homes contain a variety of different chemical compounds. For example, one participant expressed surprise that researchers found a total of 67 of the 89 target

\footnotetext{
${ }^{6}$ Two interviews involved pairs (one couple, one mother-daughter). Within each pair, one person was the primary interviewee, while the other interspersed comments; the final count of individuals interviewed does not reflect these two additional individuals.

${ }^{7}$ Interviews were more conversational and dynamic than traditional semi-structured interviews. Silent Spring Institute researchers trained the interviewer (Altman) to be conversant with the data graphs. Several interviews required the interviewer to explain how to read the graphs or to discuss information about household exposures.
} 
chemicals in sampled homes. As she noted, "I didn't even know there were that many chemicals, but I guess there's a lot more than that even."

4. Even banned substances, such as the pesticide DDT, were detected. The fact that chemicals could persist so many years after their use was identified as both new information and an unexpected research finding.

5. There are numerous sources for chemicals found in urine, blood, and household air and dust. Many expressed learning that household cleaning products and beauty supplies were potential exposure sources for chemicals found in their urine, air, and dust. One woman's response characterizes a broader pattern we observed among participants: "I never stopped to think about some of the things that I just automatically buy and use." While several participants routinely avoided aerosolized sprays, noting that they thought propellants could be "bad," women reported learning that chemicals found in indoor air and dust samples stem from nonaerosolized forms as well.

6. Many common, household sources of chemical exposures are unregulated or understudied. Some participants questioned why there is an absence of epidemiological and toxicological data for many chemicals, why there were few EPA health-based guidelines for chemicals in the study, or why few consumer or household products are safety tested.

Although study participants reported learning new information about exposures to chemicals, perhaps more provocative than what new information participants gained was their tendency to identify information gaps resulting from absent or uncertain health data. More than half of the study participants $(\mathrm{N}=15)$ requested additional information about what the study results meant. They asked, Do these results signal a problem? What is "acceptable"? Where are these chemicals coming from? And, what should I do? Participants wanted more than a descriptive account of what was found, and more than a relative account of their results compared to others; they also wanted scientists' evaluation of their data for health implications and action. As one woman remarked, "every home also has corn flakes in the kitchen; but that doesn't tell me anything." Another woman, who joined the study to understand her experience with breast cancer, noted that, "I basically feel I got nothing." Yet, in these cases, participants desired information about potential health risks that does not yet exist.

For many chemicals, the scientists' capacity to offer more health information was hampered by the limited availability of government health-based exposure guidelines, information about routes of exposure, or effective exposure-reduction strategies. ${ }^{5} \mathrm{~A}$ few participants expressed frustration with the scientists because they worried the scientists had withheld explanatory information. Their frustration festered, even when participants requested more information and the scientists re-explained the uncertainty of personal exposure information, and even when participants understood the social and political circumstances that created data gaps. As one woman noted,

I think that if I said to her [the lead toxicologist on the study]: Specifically, where does this come from and how did I get it? I'm not sure she would answer me; I don't know that she could answer me.

Researcher: There's a lot that we don't know.

Participant: Mmmm. And I don't like that. I don't like that at all.

In response to these circumstances, study participants reached out to others. As indicated in the previous excerpt, participants contacted the scientists, but they also queried friends and family (e.g., a friend with cancer, a daughter with a medical degree, or a son with scientific training). They shared study results with their physicians or oncologists. Some participants consulted Internet resources or local libraries. One participant copied the results for her 
landscaper, who had applied pesticides to her lawn and garden. Yet, as these participants reported, their friends and contacts—including their physicians—-had few new insights to offer. Left unresolved were lingering questions: Participants' narratives reflected puzzlement over how to interpret levels and make appropriate responses. The majority of interviewees also asked how other study participants responded to exposure data and whether their own queries were unique. Thus, most participants demonstrated that the study offered them new information about exposures that were not a previous concern.

In the next section, we present how participants responded to this information, including what participants said about the levels, sources, and responses to chemicals in their homes and body samples. Then, we show how participants reconciled insights about their personal exposure data with popular assumptions about the nature of chemical exposures and risk.

\section{Sources: "Where Is This Coming from?"}

One theme across interviews was a notable incongruity between women's perception of possible chemical sources and the chemicals in their air, dust, and urine. Participants often said they were perplexed by the number of chemicals detected. This puzzlement persisted despite the scientists' effort to inform participants about common household sources. Almost half of the participants $(N=11)$ reported some variant of the following statement: "I don't use a lot of products" so "I have no idea where any of this was coming from." One woman remarked,

I'm surprised that they can find that many things by looking at your dust and looking at your air. I mean, that's amazing to me that they can actually find chemicals in your air in any amount whatsoever.

The discrepancy between data and perception can be explained partially by the unknown presence of many chemicals in everyday household, construction, and personal care products. Participants did not have to spray or apply a substance in order for chemicals to accumulate in dust or indoor air. Chemicals could originate from carpeting, upholstery, electronics, plastics, cleaners, pest control, landscaping, and personal care supplies, many of which contain unlabeled additives.

However, product-use seemed unremarkable and unmemorable to most participants, which suggests their use is a habitual constituent of consumer culture. Initially, when surveyed, many participants underestimated their product use. With additional questions and time for reflection, however, participants would recall products used in routine housekeeping and personal care. Consider the following exchange, which occurred as a participant scanned the list of common exposure sources provided to her:

I just, I don't use any of these things ... when I look at it [the study results and the researchers' source list], I keep saying no to so many things. But, obviously, there is something. But, I keep saying, I don't have that, and I don't have this, and so on and so forth. I don't know.

This participant noted that her home harbored chemicals at levels "higher than in most homes." Later, she raised several possible sources, but quickly rejected each one. Each possibility violated her understanding of what activities or products would be contributors. Similarly, another woman noted:

Participant: Well, you know what you shouldn't use, like the sprays-too many sprays. That's the one thing that they [the scientists] spoke about a lot, were the sprays $\cdots$

Researcher: Like what kinds of sprays? 
Participant: Well, of course I don't use any ... Well, I don't use hairspray. I do use a bathroom spray. And, a countertop spray. Let's see what else. A window spray ... That's it. I don't have a lot.

Participants more readily looked to historical uses of chemicals before inventorying current ones. Assigning contemporary exposures to historical uses was a prevalent theme. Some participants realized that homes could harbor potentially dangerous substances no longer used in residential applications. For example, several participants, when considering possible sources, would note the age of their home and suggest that older homes harbor remnants from former uses (e.g., "it's a really old house, and God knows what it's been treated with ... over the centuries.") Indeed, the age of a home does influence what chemicals are within it. With newer homes, the scientists did not expect to see high levels of lead, asbestos, or chlordane, since the United States banned household uses of these substances. However, participants were less primed to think about exposures from contemporary sources. One participant attributed her exposures to her old house while a can of household insecticide sat, unmentioned, on an end table beside her.

\section{Levels: “Is This High?”}

When interpreting their results, participants paid attention to the level of chemicals more than they commented on the number detected. Indeed, previous research has found that people read levels as social indictors of risk that dictate their response (Clarke 1989). Similarly, chemical regulation historically has been attuned to levels - measuring the level of exposure, estimating the levels at which no health effect is anticipated, and setting limits for acceptable exposures.

When possible, participants compared their results to government health-based guidelines depicted on the results graphs. Participants used guidelines to anchor their assessment of whether their levels were cause for concern. Results near or below the guideline were less noteworthy than those above it. Many of these benchmarks, however, do not reflect current scientific knowledge about potential cancer and noncancer health risks, rendering seemingly "acceptable" levels potentially more problematic than the graphs may depict. Most participants did not question the validity of these guidelines, though some did, and a few broached whether the guidelines changed over time or why so few of the chemicals in the study had guidelines.

In addition to calibrating their concern based on whether levels were lower than regulatory benchmarks, participants based interpretations on comparisons between their samples and those of others. When asked if their results seemed "high," participants most often said "no," unless the amount in their home was considerably higher than others. If their results fell midrange, or if a detected chemical was found in most homes, as was common, their concern dropped precipitously. Consider this exchange:

Researcher: Would you say that the results were high or concerning in any way to you?

Participant: [While flipping through results] Well I think that in some instances, they were high, you know ... they're way up there. So I don't have anything to compare it to, you know, maybe they're wonderful.... So, I didn't get too alarmed because they look sort of middle range. And maybe if, you know, I'd come out up here [points to higher end of the sample distribution] or some place, and I was real nervous about that, then I probably would have read this [pointing to the list of possible sources for each chemical]. I mean, I'm interested, yes, but it didn't mean a thing to me unless it was something very, very bad.

When levels appeared "in the middle," participants perceived them as neither high nor as "raising red flags." When women scanned their graphs for levels that appeared as abnormal, 
they often saw their data points clustered among others. In these instances, participants interpreted their levels as "average" or "normal," for example, offering this typical response: "I'm the common man; I'm right in the middle." For most participants, this perception of "average-ness" allayed concerns of health risk.

One participant turned the question back on the interviewer: "I'm just wondering if any of the levels are alarmingly high?" In one instance, she observed that the levels of a particular chemical detected in her home were the highest among anyone in the study, much to her surprise. Like others, she looked for a threshold value, a social cue, to tell her at what level she should be "alarmed."

Though some women's homes may have had a large quantity of a particular chemical, or were one of the few homes in which a particular chemical was detected, unless the level appeared on the extreme upper end, women did not perceive the level as high and did not express concern. One woman's home, for example, was among only 2 of 120 homes in which a particular chemical was detected. Yet of those two hers was lowest. Her observation that someone else had a higher result allayed her concern.

Importantly, not all participants relied on levels to gauge whether their results warranted concern. One participant, when asked if the results seemed high, noted that her concern hinged not on the level of chemicals detected, but on the number of chemicals found and the ubiquity of exposure across homes.

\section{Responses: "Who Holds Jurisdiction over Chemicals in Homes and Bodies?"}

When results did trigger concern, participants sought to control or remediate the situation through technological fixes, changing consumption habits, or both, and by addressing exposures symbolically. In similar situations, Edelstein (2004) observes a popular adherence to "technological fallacies"- that exposures are technical problems to be "cleaned up" through ever more-sophisticated scientific innovation. We also find a corollary, "consumption fallacy"- that exposures to chemicals can be prevented through altered consumer habits (e.g., buying fragrance-free rather than scented cleaning products) or through a self-imposed "inverted quarantine" to isolate themselves from perceived toxic threats (Szasz 2007). The fallacy here is that consumer choice is unbounded, when the range of options consumers have to reduce exposure to chemicals like phthalates or flame retardants is limited. Often chemical additives or residues in consumer products are unlabeled and unregulated, making it hard to identify products to avoid. Economic constraints pose an additional barrier to exposure reduction, since many environmentally preferable products are not financially accessible.

Even when exposure reduction strategies are available, a subset of study participants learned that these have limited effectiveness. For example, prior to enrollment in the HES, one woman eliminated all pesticide use in her garden and regularly consumed organically grown foods. She was surprised to learn pesticides were in her urine despite these efforts. Given the lifestyle changes she made to reduce exposure, the results disheartened her:

Researcher: Can you recall some of the first impressions that you had when you opened that letter and started ...?

Participant: Well it was certainly overwhelming. It was overwhelming to know how many chemicals they found in my house, especially like I've already said, I've made really conscious efforts to eliminate so many things [pesticides]—my lawn, everything on the food that I eat. I have a water filtration system that cost me a thousand dollars to, you know, to purify my water. I've made so many, many little things like that ... and to know that even so many years after my diagnosis, to know that I'm still being exposed. It's overwhelming. 
Several participants who had their homes sampled twice recounted a similar experience. After receiving their first results, five participants reported making incremental changes. Several reduced use of household pesticides or purchased fragrance-free detergents. Another removed old furniture and carpets that were suspected to be harboring chemicals of concern. These participants expected to see these changes reflected in their new results, though their results changed very little.

Notably, participants who experienced their exposures remaining constant despite lifestyle changes reported a desire to get involved in regional environmental health advocacy. Though we do not have enough data to explore this relationship fully, this pattern suggests that a visible failure of individual actions may mobilize individuals toward collective action.

More generally, however, we noted the extent to which participants attempt to "control" personal exposures by other means. Social scientists have observed that when physical mitigation strategies are not possible or fail to reduce a perceived threat, many people instead seek to reduce threats symbolically (Vyner 1989). A variant on this theme, for some, is controlling one's perception of chemical risks. Some participants constructed symbolic boundaries around their social worlds, shoring up their homes and bodies against the chemicals thought to be lingering in the outside environment. These symbolic boundaries-whether physical or cognitive - separate person from pollutant. For instance, one participant noted that the pesticides sprayed outside her condominium were unrelated to the pesticides found in her home and urine samples:

I did have some residual pesticides in my urine, and that surprised me because ... whence might it have come? How long does it stay in your body? It's kind of a puzzle ... I know that there is a company that comes around maybe once or twice a year as needed to take care of insect invasion around the base of the whole building. We're on a level up.... So I have no pesticides here at all, never have. [Later, she noted, though her condo association used a lawn service], I don't walk over the grass ... I walk on the walkways.

Three other participants noted how such boundaries shielded them from potential exposures:

Well, I don't know if I thought that you would find anything in my house. I didn't really think that. And the funny thing is, and I, well maybe I wasn't a perfect student for the research. I spend half a year here and half a year in Connecticut. So, you could say I only have half a year of contaminants if you want to.

You know, I can see why a lot of the sprays, of why they asked about how many sprays I use, which I don't use too many. Considering what you see on TV, in the ads you know, I don't begin to buy those things.... And, I don't use hairspray; the hairdresser does that. So, I don't use that. I'm trying to think of what other things ... But, there are so many you see on TV that I just don't use.

I do have a cedar chest ... and I keep a lot of sweaters that I don't use, and scarves, old scarves and hats and stuff, they just stay in there, and I've got some moth balls in there, but it's closed with a lamp on it, and it doesn't ... it isn't in a room that's used. Upstairs. And mothballs are the only thing that I can think of that I do have in here, and they're probably disintegrated because I haven't put any in, in years ...

\section{Participants' Socio-emotional Responses}

When participants recounted their initial experience of reading the results, they typically reported (and we observed) a measured, pragmatic response to the information. Most participants found their results curious or puzzling, but rarely alarming. Their responses differed from earlier case study descriptions of encounters with uncertain chemical hazards 
(Edelstein 2004). Apprehension was not a prevailing response, as typified in the following excerpt:

Participant: There was nothing here [in the data] that was a death sentence.

Researcher: Are you glad to have learned the results of the chemicals in your Home?

Participant: Well, like I said, they weren't earth shattering.

Researcher: Right. So ... [probing further]

Participant: They didn't find anything, you know, bad.

There were a few notable exceptions; three participants described or displayed emotional reactions that more closely approximated responses to acute chemical disasters described by earlier social science research. For example, one participant reported her fear of "getting cancer" and living in a "polluted house."

Besides the lack of negative emotional responses, we observed an intriguing discrepancy between participants' recounting of their initial reaction, and the flurry of questions during the interview. For many women, the research encounter unraveled their earlier conclusions and revealed a set of underlying assumptions about chemical exposures. Many came to realize that the study challenged their understanding of the "toxics problem." For example, one woman, who initially reported that her results did not indicate cause for concern, offered this comment at the close of her interview:

So, because now I'm doing this with you, this interview, maybe I think that would encourage me to look a little bit further now. Not be so complacent, with okay, gee, you did okay. So, you can write that off ... It's just that it seems to make sense to take it another step.

\section{The Significance of Participants' Eco-social History}

Although we did not ask participants about their views on environmental pollution, they readily volunteered this information, typically by describing local or regional pollution sources. They reported being aware that they lived in a region with elevated rates of breast cancer, several sources of air and groundwater pollution, and a fragile ecosystem. The majority cited contamination problems on the Cape, especially a local military base and Superfund site, two power plants, one nuclear powered, and an extensive history of pesticide application to cranberry bogs, wetlands, and golf courses. Similarly, participants recounted numerous contamination events outside the region, for example at Love Canal (New York) and in Woburn (Massachusetts), which made national headlines and, in the case of Woburn, was recreated in A Civil Action (Harr 1996; Touchstone Pictures 1998). Over half of the participants referenced regulated or banned substances more readily than they recalled or spoke about the other classes of chemicals in the study, which have only recently entered public debate (e.g., parabens, phthalates, flame retardants). We wonder whether this has to do with an increased familiarity with banned substances, which became part of popular discourse when regulatory scrutiny attracted public attention. Though few compounds have been banned by the United States, participants remember these substances, especially if they recall using them. Although many contemporary uses of household products and chemicals were unmemorable, several participants recalled DDT stored in the garage, and another described applying chlordane around the foundation of her home.

These memorable "chemical encounters," and what participants learned about exposures from them, guided the assumptions and expectations they used to interpret study results. People invoked these experiences to interpret levels of chemicals reported in their homes and bodies, and to identify probable exposure sources and appropriate responses. When participants 
considered pollutant sources, they often looked outside the home. For the Cape Cod participants, the primary context drew upon a collective experience of community contamination of soil, air, and groundwater from activities at the Massachusetts Military Reservation, where contamination of drinking water supplies resulted in regulatory action (EPA 2000). These events contributed to an assumption that toxic contamination occurs through concentrated military or industrial activities, accidents, or dumping, not everyday use of household products. These experiences influenced problem definition about the build-up of chemicals in intimate interior spaces (e.g., homes and bodies), channeling participants' concerns towards large-scale contamination and away from everyday exposures that accumulate over time.

Finally, participants recounted substances that were banned and removed from the market for household use (e.g., TRIS flame retardants in children's sleepwear), instances where the government did act. It remains unclear whether and how these notable instances of regulatory action led participants to expect stronger regulatory oversight of household products, even though historically this is not the case.

However, prior toxic encounters, in interaction with their experience of learning exposure results, led study participants to re-examine previously held assumptions about when and how humans are exposed to chemicals and what courses of action are most likely to reduce exposure. This emergent state of understanding constitutes a salient feature of participants' exposure experience. In the discussion, we consider the theoretical, scientific, and policy implications of these findings.

\section{Discussion}

For study participants, pollution came home and got personal, as they learned that toxic chemicals were found in unexpected places and from unanticipated sources, often from products that they brought into their homes and used on their bodies. By interviewing women as they processed new information about personal exposures, we observed how science challenges existing environmental health knowledge accrued from their previous environmental experiences. This prior knowledge shaped how new personal exposure information was understood in three ways.

First, participants perceived that harm or risk was proportional to the amount of chemicals in their home. They judged the level by comparing their own results with others in the study and interpreted typical household levels as small in comparison with their perception of harmful contamination. Second, participants evaluated harm or risk based on sensibilities about the source of chemical pollutants. They assumed risks were linked to industrial, governmental, or military uses; to former household uses (e.g., pesticides sprayed around the entire foundation of a home, or asbestos tiling throughout a home); or to chemicals that are immediately sensible (e.g., fumes). Finally, many participants felt they could control what chemicals entered their homes and bodies, even though the assumption that exposures are controllable was undermined for several women over the course of the study.

Though social scientists document how rapid innovations in environmental health and exposure science contribute to our expanding understanding of where and how humans interact with pollutants (Frickel 2004; Shostak 2005), fewer have documented how personal exposure research, including measurements of human body burden, affects people's understandings of synthetic chemicals and environmental problems (Altman 2008; Boswell-Penc 2006; Casper 2003; Casper and Moore 2009; MacKendrick 2007; Shostak 2004; Washburn 2007a; 2007b). For sociologists, participants' responses about their "exposure experience" underscore that a new category of science-mediated "chemical encounters" need sociological attention, 
particularly by medical sociologists already practiced in the study of narrative and lay experience.

Our research suggests that individuals' experiences have undergone a marked shift. Social scientists, during the 1970s through 1990s, noted the lack of shared or popular knowledge that could help inform and explain human encounters with toxic chemicals (Edelstein 2004; Erikson 1994). We find that the baseline has changed; study participants' experiences suggest how a common understanding of chemical contamination can result from a regional, "eco-social" experience and media coverage of "environmental crises" over the past two decades. The prevailing assumption that follows from such experiences is that chemical pollutants matter when they exist in large quantity and when they are released into the environment by industrial or military accidents, large-scale use, or dumping. In contrast, personal exposure science illuminates how toxic contamination happens in ways far less dramatic, and perhaps more insidious than the existing social assumptions suggest. One result was Cape residents' somewhat muted responses, similar to results reported by Beamish (2002). At the same time, we found that, while older assumptions about the public health significance of synthetic chemicals have generated an unintended "blind-spot" that infuses participants' assumptions about everyday chemicals and their consequences (Beamish 2002; Frickel and Vincent 2007). Access to personal exposure information made that blind spot visible.

We also integrate environmental health science into the study of individuals' embodied experience of health and the environment. Doing so recognizes a broader trend in which science increasingly discovers and defines problems, and thus, mediates the experience of health and the body. This is an area ripe for more synthesis and theoretical development (Williams, Birke, and Bendelow 2003). Medical sociologists already recognize the importance of science and technology for embodied experience, with a particular focus on medical technologies (Timmermans and Berg 2003) that diagnose preclinical disease or disease risk (e.g., Cox and McKellin 1999). These studies point to how science and technology can medicalize and disembody illness experience, and, in the latter case, catalyze a new sense of embodiment or illness.

Reliance on prior experience by participants to interpret study findings likely will be true in other settings. However, the specific social cues and references available to study participants will vary by social, eco-historical and geographical context. Thus, some of our findings about what social cues mattered to interpretation of exposure results may be more typical of women than men, and may be limited to this specific demographic group of predominantly older, white, middle class women. Our research underscores the significance of participants' shared ecosocial history of living in a region viewed as a "contaminated place" and having a high incidence of breast cancer. Moreover, this generation witnessed the advent of environmental health disasters as big media-Love Canal and Woburn documented in A Civil Action-and the banning of DDT and other substances with common uses, which also shaped their perceptions. The number of women with previous breast cancer experience is another contextual element in this study that would not be relevant in other populations, though we found relatively little mention of breast cancer in connection with participants' interpretations of their exposure reports.

Perhaps women in this study also demonstrate a cohort effect based on a shared set of housekeeping norms centered on purchasing "cleanliness" and the "right" product for each household task. Studies like the Household Exposure Study reveal the potentially toxic consequences of these norms by implicating the assumptions that comprise that lifestyle: hygienic homes, lush lawns, gleaming tile, plastic-wrapped leftovers, and vinyl-covered furniture. 
Participant responses in this study also may be influenced by the community-based participatory methods that were integral to the Household Exposure Study. The project works with a public advisory council, employs a Cape Cod outreach coordinator, and holds frequent public meetings to keep study participants and community residents informed about the research design, progress, and results. These longstanding community relationships may contribute to the moderate emotional responses we observed, in light of earlier research that shows that the method in which a risk message is delivered can be more important than its content (Northern Contaminants Program 2003). If reporting occurs in partnership with affected populations and communication lines remain open after the initial exchange, fears may be mitigated. This observation also squares with a classic sociological finding that harm can follow as much from institutional responses to chemical pollution as from the physical insult (Erikson 1994; Freudenburg 1993). Thus, it is important to bear in mind both the context of this study population and the report-back methods used when generalizing from our findings.

\section{Implications for Science}

The National Research Council (2006) recently called for more research on how participants in surveillance programs and personal exposure studies respond to results and the "mental models" that inform participants' interpretation of uncertain exposure data. This need is reinforced by California's 2006 passage of the country's first statewide biomonitoring program, followed by the introduction of similar legislation in Indiana, Washington, and New York. In this article, we have responded to the NRC's call.

Our interviews indicate that study participants wanted their results and appreciated the opportunity to receive them. Participants' desire for this information parallels the increase of patient requests for medical information and participation in medical decision-making (Bury 2004; Charles and DeMaio 1993). Second, when participants received exposure information, they did not react with the alarm observed after acute environmental disasters. This empirical evidence counters the position of some scientists and public health officials, who seek to avoid or limit risk communication of uncertain personal exposure information to protect participants from adverse emotional responses. We also find that participants want more rather than less information, including technical explanations about what is either unknown or remains uncertain.

Our observation that participants reconsidered their interpretation of study results during the interviews suggests that some would benefit from a report-back procedure that incorporates discussion. Furthermore, just as they compared their results to others, many women asked the interviewer about the responses of other study participants. With their questions, they sought to validate how they had responded and to learn about alternative courses of action. We hope that researchers, in collaboration with institutional review boards, will develop options for study participants to compare experiences while also respecting confidentiality.

Our results also suggest that it will be helpful for scientists to contextualize study results and scientific uncertainty within the framework of participants' starting assumptions about toxic chemicals. Much of the debate about whether and how to report personal exposure information has focused on placing research findings within their proper "scientific" context by explaining the toxicological and epidemiological uncertainties; however, our research suggests an additional definition of context that report-back protocols might incorporate: the unique social and historical setting. One implication is that communicating personal exposure information is not the sole purview of scientific or public health experts, but should include the perspectives of peer-group or community members who understand how participants' historical experiences with environmental problems will filter their interpretation of new exposure data. In addition, involving community members will reveal how perspectives and experiences of the same environmental problems might differ within the community or study population, a possibility 
raised by Auyero and Swistun (2007). By supporting community participation in reporting, our findings parallel the Canadian Northern Contaminants Program (2003), where risk communication occurs in the context of long-term relationships between scientists and communities, shared decision-making, dense communication networks of scientists and community representatives, and reporting that is targeted to specific communities and subgroups based on their unique eco-social histories (see also Usher et al. 1995).

\section{Future Study}

In this article, we report on the shared assumptions observed across participants' exposure experiences. As we move forward in our work, we hope to explore the mechanisms that transmit these shared assumptions. Auyero and Swistun's (2007) ethnographic work on the contrasting experience of the same contaminated community in Argentina points us to understand where, and under what conditions, shared eco-social histories emerge. As we progress, we also will elucidate the meso-level factors ${ }^{8}$ that channel, transmit, or filter participants' regionallyspecific eco-social histories. Through this effort, we hope to contribute to the advancement of environmental public health science, while also participating in the development of the medical sociology literature on embodied health experiences where it articulates with science and the environment.

To advance our understanding and test modified reporting methods that build on our experience, we are repeating this study with our collaborative partner, Communities for a Better Environment, in a California community of predominantly low income Latino and African American residents. This community has a different sociopolitical experience with exposures to chemicals because it borders industrial and transportation facilities associated with oil refinement and goods movement. We anticipate that communities with a history of contamination from numerous sources, compounded by government inaction and public distrust, will be less surprised by contamination in homes, though their eco-social history might operate in similar ways to conceal the role of everyday consumer products.

We anticipate that public responses to personal exposure information will vary, in our own further studies and the work of others, depending on the social and eco-historical experience of the population. Our findings suggest that a one-size-fits-all reporting strategy would not be ideal because social position and eco-social history alter the range of social cues and scripts available for participants to reference, and this influences how participants understand and assign meaning to their results. As personal exposure science advances, it is imperative for researchers, in partnership with communities and affected populations, to learn about the new embodied awareness and experience of contamination in order to communicate personal exposure information effectively and to anticipate participants' responses.

\section{References}

Altman, Rebecca Gasior. Doctoral Dissertation. Department of Sociology, Brown University; 2008. Chemical Body Burden and Place-Based Struggles for Environmental Health and Justice. A MultiSite Ethnography of Biomonitoring Science.

Auyero, Javier; Debora, Swistun. Confused Because Exposed: Towards an Ethnography of Environmental Suffering. Ethnography 2007;8(2):123-44.

Beamish, Thomas D. Silent Spill: The Organization of an Industrial Crisis. Cambridge, MA: MIT Press; 2002.

Bird, Chloe E.; Peter, Conrad; Allen, Fremont. Handbook of Medical Sociology. Vol. 5th. Upper Saddle River, NJ: Prentice Hall; 2000.

\footnotetext{
${ }^{8}$ We thank Sara Shostak for suggesting this new direction.
} 
Boswell-Penc, Maia. Tainted Milk: Breastmilk, Feminisms, and the Politics of Environmental Degradation. Albany, NY: State University of New York Press; 2006.

Brody, Julia; Brown, Phil; Rudel, Ruthann; Morello-Frosch, Rachel; Altman, Rebecca Gasior; Frye, Margaret; Osimo, Cheryl; Perez, Carla; Seryak, Liesel. The New Ethics for Reporting Personal Environmental and Biological Exposures to Study Participants. The American Journal of Public Health 2007;97(9):1547-54.

Brown, Phil. Toxic Exposures: Contested Illnesses and the Environmental Health Movement. New York, NY: Columbia University Press; 2007.

Brown, Phil; Mikkelsen, Edwin J. No Safe Place: Toxic Waste, Leukemia, and Community Action. Berkeley: University of California Press; 1990.

Brown, Phil; Zavestoski, Stephen; McCormick, Sabrina; Mayer, Brian; Morello-Frosch, Rachel; Gasior, Rebecca J. Embodied Health Movements: Uncharted Territory in Social Movement Research. Sociology of Health and Illness 2004;26(1):1-31. [PubMed: 15027988]

Bullard, Robert D. Dumping in Dixie: Race, Class, and Environmental Quality. Boulder, CO: Westview Press; 1990.

Bury, Michael. Researching Patient-Professional Interactions. Journal of Health Services Research and Policy 2004;9(Supplement 1):48-54. [PubMed: 15006228]

Casper, Monica J., editor. Synthetic Planet: Chemicals, Politics, and Hazards of Modern Day Life. New York: Routledge; 2003.

Casper, Monica J.; Lisa, Jean Moore. Missing Bodies: The Politics of Visibility. New York: New York University Press; 2009.

Centers for Disease Control and Prevention. Atlanta, GA: U. S. Department of Health and Human Services Centers for Disease Control and Prevention; 2005. Third National Report on Human Exposures to Environmental Chemicals. Retrieved June 1, 2007 (http://www-cdc-gov/exposurereport/report-htm)

Centers for Disease Control and Prevention. Chemicals Measured in Selected Participants, NHANES 2003-2004. 2007. Retrieved July 31, 2008 (http://www.cdc.gov/exposurereport/pdf/NHANES03-04List_03_2007.pdf)

Charles, Cathy; DeMaio, Suzanne. Lay Participation in Health Care Decision-Making: A Conceptual Framework. Journal of Health Politics, Policy, and Law 1993;18:881-904.

Clarke, Lee. Acceptable Risk? Making Decisions in a Toxic Environment. Berkeley: University of California Press; 1989.

Couch, Stephen R.; Kroll-Smith, J Stephen. The Chronic Technological Disaster: Toward a Social Scientific Perspective. Social Science Quarterly 1985;66:564-75.

Couch, Stephen R.; Kroll-Smith, J Stephen, editors. Communities at Risk: Collective Responses to Technological Hazards. New York: Peter Lang; 1991.

Cox, Susan M.; McKellin, William. 'There's This Thing in Our Family': Predictive Testing and the Construction of Risk for Huntington's Disease. Sociology of Health and Illness 1999;21(5):622-46.

Edelstein, Michael. Contaminated Communities. Vol. 2nd. Boulder, CO: Westview; 2004.

Environmental Protection Agency. Washington, DC: EPA; 2000. EPA Orders Extensive Cleanup of Mass. Military Reservation on Cape Cod. Retrieved June 1, 2007 (http://www.epa.gov/region1/pr/2000/010700.html)

Environmental Working Group. Washington, DC: Environmental Working Group; 2003. Body Burden: The Pollution in People. Retrieved September 30, 2006 (http://www.ewg.org/reports/bodyburden1/dynam-contams.php)

Erikson, Kai. A New Species of Trouble: The Human Experience of Modern Disasters. New York: W.W. Norton; 1994.

Fischer, Douglas. State to Trace Toxins from Streams to Veins. The Oakland Tribune. 2006September 29, 2006

Freudenburg, William R. Risk and Recreancy: Weber, the Division of Labor, and the Rationality of Risk Perceptions. Social Forces 1993;71:909-32.

Frickel, Scott. Chemical Consequences: Environmental Mutagens, Scientist Activism and the Rise of Genetic Toxicology. New Brunswick, NJ: Rutgers University Press; 2004. 
Frickel, Scott; Vincent, M Bess. Hurricane Katrina, Contamination, and the Unintended Organization of Ignorance. Technology in Society 2007;29:181-88.

Geiser, Ken. Materials Matter: Toward a Sustainable Materials Policy. Cambridge, MA: MIT Press; 2001.

Gottlieb, Robert. Forcing the Spring: The Transformation of the American Environmental Movement. Washington, DC: Island Press; 2005.

Harr, Jonathan. A Civil Action. New York: Vintage Books; 1996.

Harris, Jeffrey S. Toxic Waste Uproar: A Community History. Journal of Public Health Policy 1983;4 (2):181-201. [PubMed: 6688429]

Hilgartner, Stephen; Bosk, Charles. The Rise and Fall of Social Problems: A Public Arenas Model. American Journal of Sociology 1988;94(1):53-78.

Irwin, Alan; Wynne, Brian, editors. Misunderstanding Science? Public Reconstruction of Science and Technology. Cambridge, England; Cambridge University Press: 1996.

Jasanoff, Sheila, editor. States of Knowledge: The Co-Production of Science and Social Order. New York: Routledge; 2004.

Kroll-Smith, Steven; Brown, Phil; Gunter, Valerie, editors. Illness and the Environment: A Reader in Contested Medicine. New York: New York University Press; 2000.

Kroll-Smith, Steve; Floyd, H Hugh. Bodies in Protest: Environmental Illness and the Struggle over Medical Knowledge. New York: New York University Press; 1997.

Lawton, Judith. Lay Experiences of Health and Illness: Past Research and Future Agendas. Sociology of Health and Illness 2003;25:23-40. [PubMed: 14498928]

Levine, Adeline. Love Canal: Science, Politics, and People. Lexington, MA: Lexington Books; 1982.

Lioy, Paul J.; Freeman, Natalie C G.; Millette, James. Dust: A Metric for Use in Residential and Building Exposure Assessment and Source Characterization. Environmental Health Perspectives 2002;110 (10):969-83. [PubMed: 12361921]

MacKendrick, Norah. Contaminants, the Human Body, and the Framing of Risk: A Study of Canadian News Coverage, 1986-2006. Presented at the annual meeting of the American Sociological Association; August 11-14; Montreal, Québec, Canada. 2007.

McCormick, Sabrina; Brown, Phil; Zavestoski, Stephen. The Personal Is Scientific, The Scientific Is Political: The Public Paradigm of the Environmental Breast Cancer Movement. Sociological Forum 2003;18:545-76.

MacIntyre, Sally; Ellaway, Anne; Cummins, Steven. Place Effects on Health: How We Can Conceptualize, Operationalize and Measure Them? Social Science and Medicine 2002;55(1):125139. [PubMed: 12137182]

McKelvey, Wendy; Brody, Julia G.; Aschengrau, Ann; Swartz, Christopher H. Association between Residence on Cape Cod, Massachusetts, and Breast Cancer. Annals of Epidemiology 2003;14(2): 89-94. [PubMed: 15018880]

Morello-Frosch, Rachel. Discrimination and the Political Economy of Environmental Inequality. Environment and Planning C: Government and Policy 2002;20:477-96.

Morello-Frosch, Rachel; Brody, Julia G.; Frye, Margaret; Brown, Phil; Altman, Rebecca Gasior; Rudel, Ruthann; Napolis, AJ. The Right to Know, the Right to Act, and the Right Not-to-Know: Ethical and Scientific Dilemmas of Reporting Data in Biomonitoring and Environmental Exposure Studies. Presented at the annual meeting of the American Sociological Association; August 11-14; Montreal, Québec, Canada. 2006.

Murphy, Michelle. Sick Building Syndrome and the Problem of Uncertainty: Environmental Politics, Technoscience, and Women Workers. Durham, NC: Duke University Press; 2006.

Murphy, Raymond. Sociology and Nature: Social Action in Context. Boulder, CO: Westview Press; 1997.

National Research Council of the National Academies. Human Biomonitoring for Environmental Chemicals. Washington, DC: National Academies Press; 2006.

Northern Contaminants Program. Canadian Arctic Communities Assessment Report II. Knowledge in Action. Ottawa, CA: Indian and Northern Affairs Canada; 2003.

Pulido, Laura. Environmentalism and Economic Justice: Two Chicano Studies in the Southwest. Tucson: University of Arizona Press; 1996. 
Quandt, Sara A.; Doran, Alicia M.; Rao, Pamela; Hoppin, Jane A.; Snively, Beverly M.; Arcury, Thomas A. Reporting Pesticide Assessment Results to Farmworker Families: Development, Implementation, and Evaluation of a Risk Communication Strategy. Environmental Health Perspectives 2004;112(5): 636-42. [PubMed: 15064174]

Robertson, Ann. Embodying Risk, Embodying Political Rationality: Women's Accounts of Risks for Breast Cancer. Risk and Society 2000;2(2):219-35.

Rudel, Ruthann; Camann, David E.; Spengler, Jack D.; Korn, Leo R.; Brody, Julia G. Phthalates, Alkylphenols, Pesticides, Polybrominated Diphenyl Ethers, and Other Endocrine-Disrupting Compounds in Indoor Air and Dust. Environmental Science and Technology 2003;37(20):4543-53. [PubMed: 14594359]

Shostak, Sara. Environmental Justice and Genomics: Acting on the Futures of Environmental Health. Science as Culture 2004;13(4):539-62.

Shostak, Sara. The Emergence of Toxicogenomics: A Case Study of Molecularization. Social Studies of Science 2005;35(3):367-403. [PubMed: 16060075]

Silent Spring Institute. Newton, MA: Silent Spring Institute; 2005. Sample of Household Exposure Study Report-Back Materials. Retrieved May 16, 2007 (http://www.silentspring.org/newweb/research/report-back_sample.pdf)

Szasz, Andy. Ecopopulism: Toxic Waste and the Movement for Environmental Justice. Minneapolis: University of Minnesota Press; 1994.

Szasz, Andy. Shopping Our Way to Safety: How We Changed from Protecting the Environment to Protecting Ourselves. Minneapolis: University of Minnesota Press; 2007.

Timmermans, Stefan; Berg, Marc. The Practice of Medical Technology. Sociology of Health and Illness 2003;25(3):97-114. [PubMed: 14498932]

Touchstone Pictures. A Civil Action. 1998

U.S. General Accounting Office. GAO/RCED-99-254. Washington, DC: U.S. Government Printing Office; 1999. Indoor Pollution: Status of Federal Research Activities.

Usher, Peter J.; Baikie, Maureen; Demmer, Marianne; Nakashima, Douglas; Stevenson, Marc G.; Stiles, Mark. Communicating about Contaminants in Country Food: The Experience in Aboriginal Communities. Ottawa, Canada: Inuit Tapiriit Kanatami; 1995.

Vyner, Henry. Invisible Trauma: The Psychosocial Effects of the Invisible Environmental Contaminants. Lexington, MA: D.C. Health and Company; 1989.

Washburn, Rachel. In Pursuit of the Molecule: Making and Making Sense of Chemical Body Burdens in the United States. Presented at The New Chemical Bodies: Biomonitoring, Body Burden, and Endocrine Disruptors Conference; Philadelphia, PA. March 22-23, 2007; 2007a.

Washburn, Rachel. Human Biomonitoring and the Lived Experience of Body Burdens. Presented at the Annual Meeting of the Society for the Social Studies of Science; Montreal, Québec, Canada. October 11-13, 2007; 2007b.

Williams, Simon J.; Birke, Lynda; Bendelow, Gillian A., editors. Debating Biology: Sociological Reflections on Health, Medicine, and Society. London: Routledge; 2003.

Wynne, Brian. May the Sheep Safely Graze? A Reflexive View of the Expert-Lay Knowledge Divide. In: Lash, S.; Szerszynski, B.; Wynne, B., editors. Risk, Environment, and Modernity: Towards a New Ecology. Thousand Oaks, CA: Sage; 1996. p. 4-83.

Zavestoski, Stephen; Brown, Phil; McCormick, Sabrina. Gender, Embodiment, and Disease: Environmental Breast Cancer Activists' Challenges to Science, the Biomedical Model, and Policy. Science as Culture 2004;13:563-86.

\section{Biographies}

Rebecca Gasior Altman earned her PhD from Brown University in 2008. Her dissertation examines how communities and advocacy groups in Appalachia, Maine, and Alaska use biomonitoring to address environmental health and justice. Other research interests track advocacy to correct the environmental health consequences posed by the health care sector. 
Rachel Morello-Frosch is associate professor in the Department of Environmental Science, Policy, and Management and the School of Public Health at the University of California, Berkeley. An epidemiologist and environmental health scientist, her research examines race and class determinants of the distribution of health risks associated with environmental hazards, particularly air pollution, among diverse communities in the United States. Her current work focuses on: the health impacts of ambient air toxics exposures, the relationship between racial segregation and environmental health inequalities, community-based environmental health research, children's environmental health, and the intersection between economic restructuring and community environmental health.

Julia Green Brody is the executive director of Silent Spring Institute, a nonprofit research organization founded by the Massachusetts Breast Cancer Coalition to study women's health and the environment in a context of partnership between scientists and activists. Recent projects include studies of household exposure to endocrine disruptors, including reporting individualand community-level results. Her research interests focus on environmental pollutants and breast cancer, and public engagement in science.

Ruthann Rudel is a leader in exposure, toxicology, and risk assessment related to mammary gland carcinogenesis and endocrine active chemicals. In her role as the senior environmental toxicologist at Silent Spring Institute, she recently directed a major review of animal mammary gland carcinogens that compiled existing research, reviewed key issues in study design, and synthesized exposure information. She also directs the Institute's Household Exposure Studies, which aim to characterize household exposures to about 100 endocrine disrupting chemicals.

Phil Brown is Professor of Sociology and Environmental Studies at Brown University. His most recent book is Toxic Exposures: Contested Illnesses and the Environmental Health Movement. His research interests include labor-environment coalitions, health social movements, connections between breast cancer activism and environmental justice, and biomonitoring and household exposure.

Mara Averick graduated from Brown University in 2007 with a bachelor's degree in science and society studies. She served as an undergraduate research assistant on this project while also working on her undergraduate thesis, which explored scientists' perceptions of the social and ethical implications of nanotechnology. 


\section{A Guide to Reading Your Results}

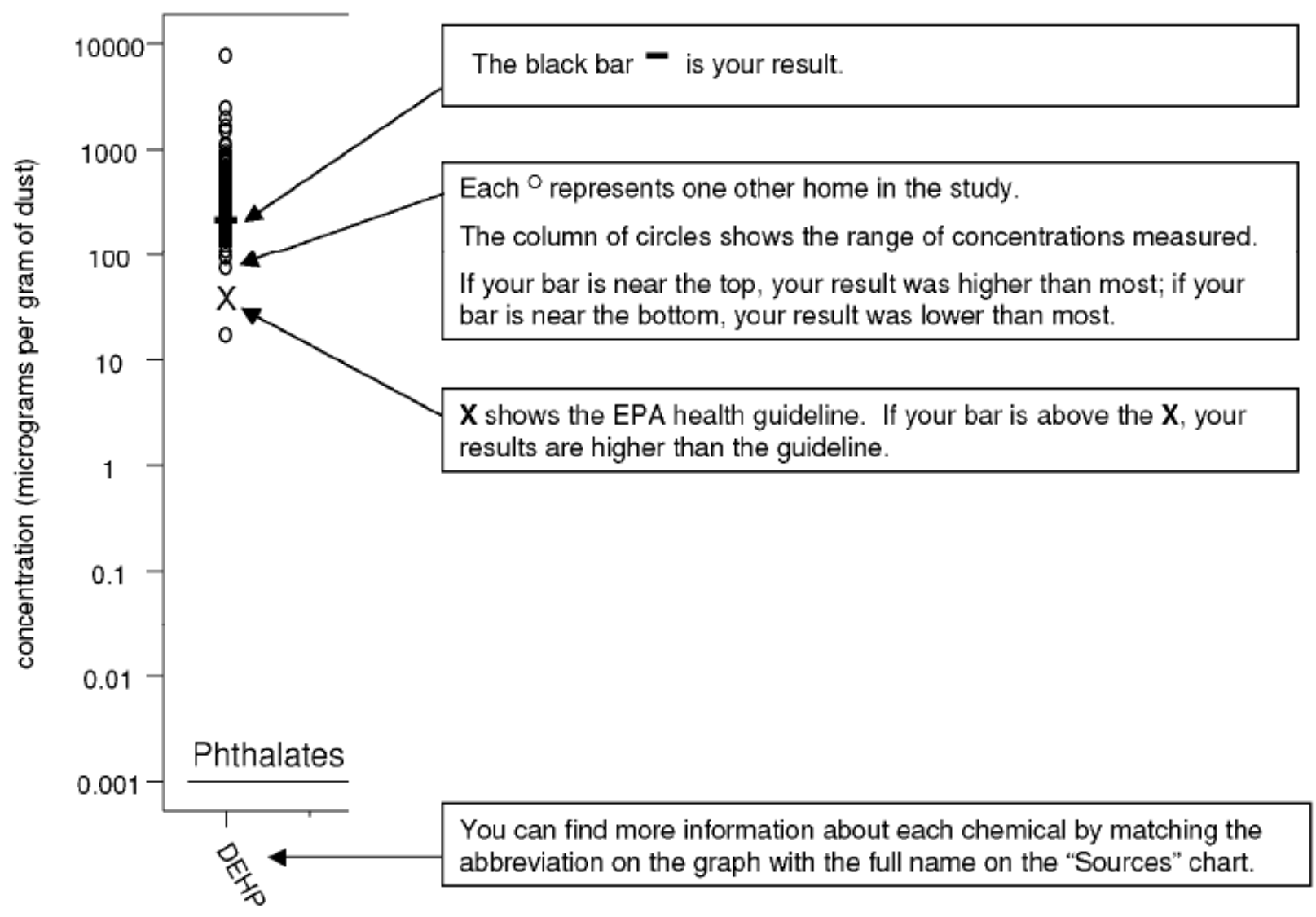

Figure 1. Figure Illustrates Instructions Participants Received for Reading Individual Exposure Results in the Cape Cod Household Exposure Study 